\title{
).( NESU Are the results of pediatric renal transplantation identical to the \\ adult population?
}

Antunes H., Tavares-Da-Silva E., Carvalho J., Parada B., Bastos C., Figueiredo A.

Department of Urology and Renal Transplantation, Coimbra University Hospital Center, Portugal

\section{INTRODUCTION AND OBJECTIVES}

Pediatric renal transplantation differs from adults in several aspects, such as immune response, pharmacological metabolism, and surgical specificities. This work aims to review the experience of our service in pediatric renal transplantation and to compare the results with the adult population.

\section{MATERIALS AND METHODS}

Between January 1981 and May 2017, 3008 kidney transplants were performed in our hospital, of which 101 were performed at pediatric ( $<18$ years) recipients. In this work, we performed a retrospective evaluation of overall survival rates and allograft survival as well as risk factors for renal graft loss. Factors such as ischemia time, donor age, human leukocyte antigen (HLA) type, and PRA (Panel Reactive Antibody) and serum creatinine values were analyzed.

\section{CONCLUSION}

Despite the differences found between the two populations, the graft survivals in both groups are favorable and statistically similar. Pediatric renal transplantation thus represents a renal replacement option with good results.

\begin{tabular}{|c|c|c|c|}
\hline Variable & $\begin{array}{l}\text { Pediatric } \\
\text { recipients }\end{array}$ & $\begin{array}{l}\text { Adult } \\
\text { recipients }\end{array}$ & Sig \\
\hline Number of patients (\%) & $101(3.4)$ & $2851(96.6)$ & \\
\hline Age of recipients (years, mean $\pm S D$ ) & $13 \pm 3$ & $43 \pm 17$ & «* \\
\hline \multicolumn{4}{|l|}{ Gender (\%) } \\
\hline Male & $59(58.4)$ & $1925(67.5)$ & $\dagger$ \\
\hline \multirow{2}{*}{\multicolumn{4}{|c|}{ Donor (\%) }} \\
\hline & & & \\
\hline Living & $12(11.9)$ & $101(3.5)$ & ** \\
\hline Deceased & 89 (88.1) & $2750(96.5)$ & \\
\hline Donor age (years, mean $\pm \mathrm{SD}$ ) & $26 \pm 12$ & $43 \pm 17$ & ** \\
\hline Preemptive transplant (\%) & $8(7.9)$ & $9(0.4)$ & \\
\hline Duration of dialysis (months, mean $\pm \mathrm{SD}$ ) & $18 \pm 21$ & $48 \pm 39$ & ** \\
\hline Cold-ischemia time (hours, mean $\pm \mathrm{SD}$ ) & $17.3 \pm 7.2$ & $18.6 \pm 6.5$ & $\dagger$ \\
\hline Surgery duration (hours, mean $\pm \mathrm{SD}$ ) & $2.6 \pm 0.5$ & $2.5 \pm 0.7$ & $t$ \\
\hline Posttransplant malignancies (incidence) & $1(1.0)$ & $159(5.6)$ & \\
\hline Acute rejections incidence & 42.6 & 18.8 & ** \\
\hline PRA value (mean $\pm S D)$ & $3 \pm 9$ & $7 \pm 16$ & * \\
\hline \multicolumn{4}{|l|}{ CKD cause $(\%)$} \\
\hline Glomerular & $26(25.7)$ & $647(22.7)$ & \\
\hline Tubulointersticial & $38(37.6)$ & 441 (15.5) & \\
\hline Congenital polycystic & $4(4.0)$ & $241(8.5)$ & ** \\
\hline Systemic/metabolic disease & $11(10.9)$ & $560(19.6)$ & \\
\hline Idiopathic & $22(21.8)$ & $962(33.7)$ & \\
\hline Graft survival at 5 yrs (\%) & 77.4 & 78.9 & $\dagger$ \\
\hline Overall survival at 5 yrs (\%) & 96.8 & 88.8 & ** \\
\hline
\end{tabular}

Legend: $\uparrow$ - $p>0,05 ;{ }^{*} p<0,05 ;{ }^{* *} p<0,001$

Table 2. Causes of death in pediatric renal transplant recipients (\%)

\begin{tabular}{lc}
\hline Malignancy & $1(8.3)$ \\
Infections & $2(16.7)$ \\
Cardiovascular & $4(33.3)$ \\
Unknown & $3(25.0)$ \\
Others & $2(16.7)$ \\
\hline
\end{tabular}

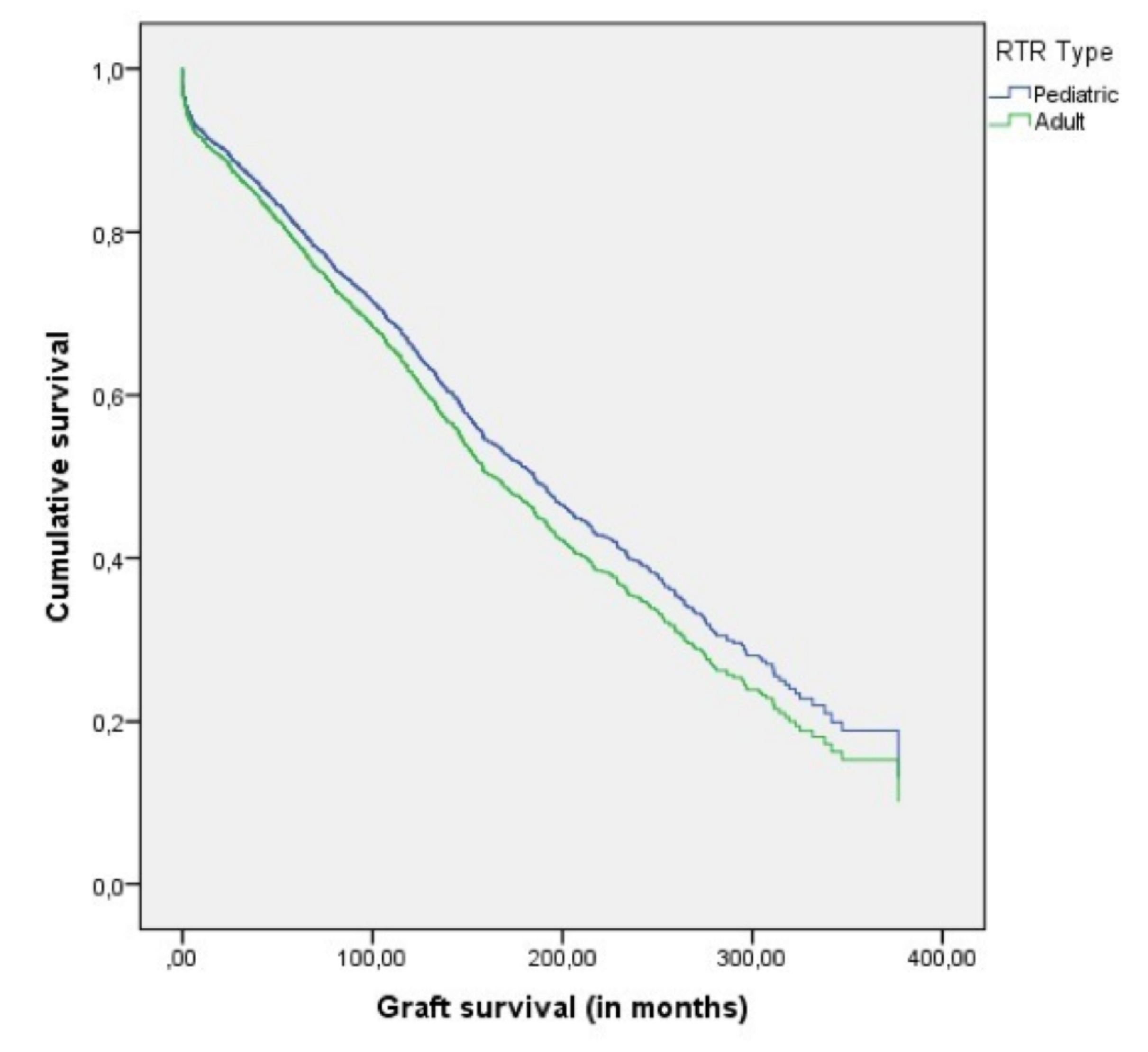

Figure 1 - Allograft survival of pediatric and adult population of RTR

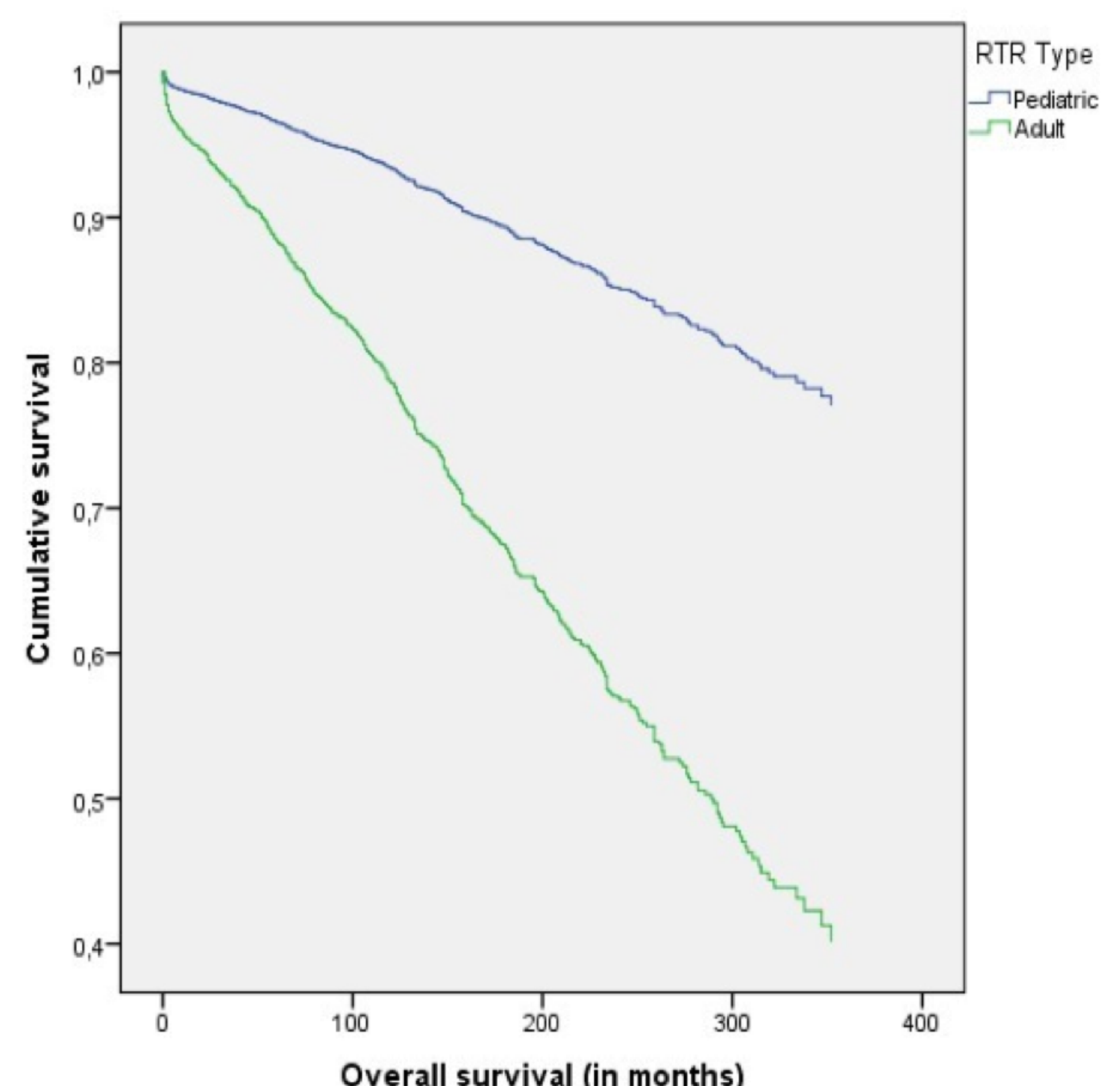

Rigure 2 - Overall survival of pediatric and adult population of RTRS 